\title{
Empirical Analysis on The Existence of The Phillips Curve
}

\author{
Mohd Shahidan Shaari*, Diana Nabila Chau Abdullah, Razleena Razali, Mohamad Luqman Al-Hakim Md Saleh
}

\begin{abstract}
The Phillips curve shows the trade-off relationship between the inflation and unemployment rates. A rise in inflation due to the high economic growth, more jobs are available and therefore unemployment will fall. However, the existence of the Phillips curve in high-income countries has not been much discussed. Countries with high income should have low unemployment rate, suggesting a high inflation. However, some high-income countries, the United States in 1970s for example, could not avert stagflation whereby high unemployment rate and inflation occurred in the same time. This situation is contrary to the Phillips curve. Therefore, this study aims to investigate the existence of the Phillips curve in high-income countries for the period 1990-2014 using the panel data analysis. The most interesting finding of this study is the existence of a bidirectional relationship between unemployment rate and inflation rate in both long and short runs. Therefore, the governments should choose to stabilize inflation rate or reduce unemployment rate
\end{abstract}

\section{Introduction}

Phillips [12] introduced the Phillips curve, which illustrates the trade-off relationship between the inflation and unemployment rates. As inflation rises because of the high economic growth, better job opportunities are available to people, implying a low unemployment rate. Stable inflation rate and low unemployment rate are the macroeconomic goals of developing and developed countries. The Phillips curve can cast a light on the problem of stabilizing inflation or reducing unemployment rate. A country that decides to stabilize inflation anticipates a higher unemployment rate, and should therefore be poised to confront the economic problem. Policy makers need to this matter carefully. A wrong decision on policies can aggravate the economy. Numerous studies, such as those of Resurreccion 13] in Philippines, Al-zeaud and Al-hosban [1] in Jordan, and Furuoka and Munir [5] in Malaysia, have investigated the existence of the Phillips curve in various countries. Their findings were consistent, that is, the Phillips curve exists in their respective countries. Meanwhile, a limited number of studies explored this existence in high-income countries, such as Haug and King et. al [6] in the United States, and their findings confirmed the existence of the Philip curve. However, the study focused only on one country and did not include other high-income countries. Countries with high incomes should have low unemployment rate, suggesting a high inflation rate. However, some high-income countries, the United States in 1970s for example, could not avert stagflation, thus high unemployment rate and inflation occurred in tandem. Frideman et. al [3] argued that the existence of the Phillips curve might be valid only in the short run. Inflation can drive workers to demand higher wages to adjust their real income. Hence, it can result in higher production cost. Firms have to incur the rising cost for every additional worker. As a result, the profits of firms fall and ensue layoffs. This situation is contrary to the Phillips curve. Therefore, this study aims to investigate the existence of the Phillips curve in high-income countries in both short and long runs.

The relationship between the unemployment and inflation rates in high-income countries is intriguing and merits attention because their economies are prosperous. Fig. 1, 2, and 3 show trends in inflation and unemployment rates in Switzerland, the United States, and Sweden, respectively. In 2009, the inflation rate was low while the unemployment rate was high in all the countries, suggesting the existence of the Phillips curve. The United States also experienced the same trend, recording the highest inflation rate at $5.4 \%$ and unemployment rate at $5.6 \%$ in 1990 . In Switzerland, the highest inflation rate was recorded at $5.9 \%$ in 1991 , while the unemployment rate was $1.8 \%$, which was low. In Sweden, the highest inflation rate was recorded at $10.5 \%$ in 1990 , while the unemployment rate was very low at $1.8 \%$. However, inflation rate hit a negative value of $0.5 \%$ in 2009 , while the unemployment rate was very high at $8.4 \%$.

* Corresponding author: shahidanshaari@gmail.com 


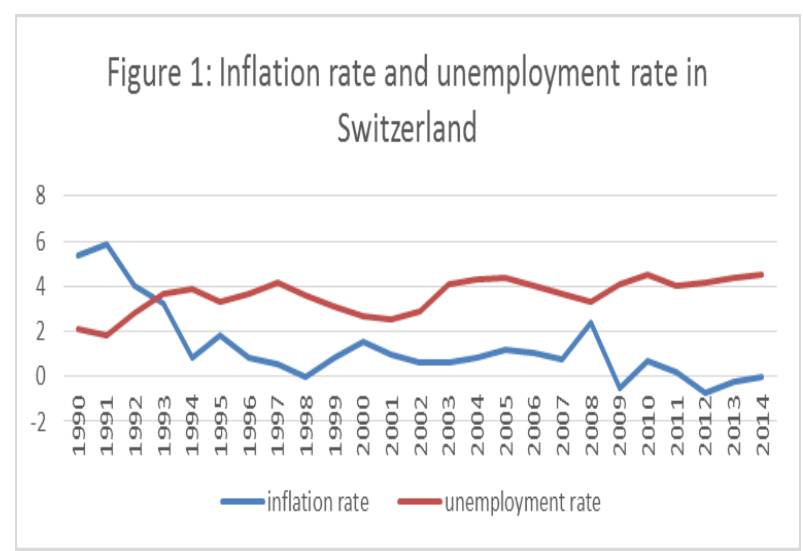

Figure 2: Inflation rate and unemployment rate in the United States

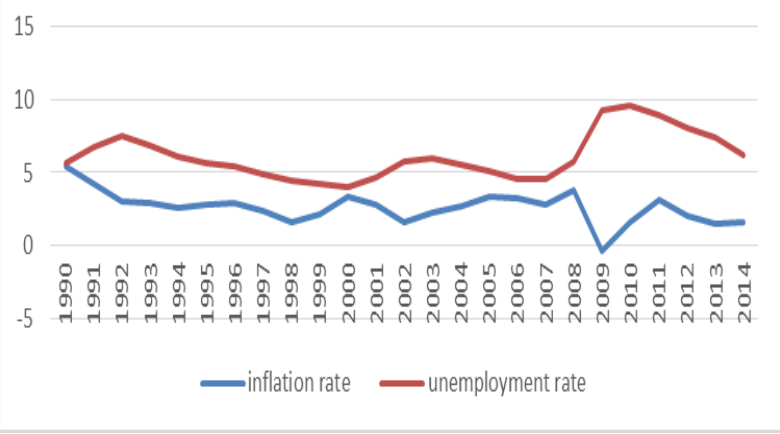

Figure 3: Inflation rate and unemployment rate in Sweden

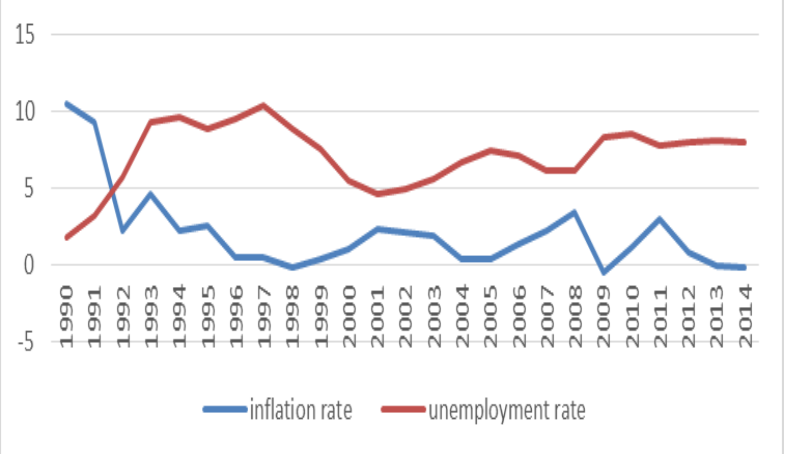

\section{Literature Reviews}

Numerous studies have been done to identify the existence of the Philip curve in various countries such as Greece by Dritsaki and Dritsaki [2] Jordan by Al-Zeaud \& Al-hosban, [1], Malaysia by Furuoka et. al [4] etc. However, their findings were mixed probably due to the economic condition. Most of previous studies discovered the existence of Philip curve. Furuoka and Munir [5] explored the connection between unemployment rate and inflation rate in Malaysia. Malaysia was chosen as it is a developing country and many previous studies have focused on developed countries. The data from 1975 to 2004 were analysed using the Johansen co-integration and error correction model tests. The results showed that there is a connection running from the unemployment rate to inflation rate in both short and long run. Therefore these findings confirmed the existence of the Phillips curve in Malaysia. Shaari et al. [15] also examined the same connection in the same country. The study analysed the data from 1982 to 2010 using the Johansen c-integration and Granger causality tests. The finding revealed the existence of a negative connection between inflation and unemployment. Schreiber and Wolters [14] examined the existence of a connection between unemployment and inflation in Germany for the period 1977:2-2002:3. The study employed vector auto regression model and vector error correction model and the findings showed that there is a negative connection between inflation and unemployment in the long run. Resurreccion et. al [13] extended the previous study by examining the connection between unemployment and inflation and economic growth within 1980-2009 but the study was done in Philippines. The analysis was based on the ordinary least square test was employed and the findings showed that an increase in the inflation rate or economic growth can cause the unemployment rate to decrease. This inverse connection corresponded with the Phillips curve.

Karahan et al. [8] examined the connection between unemployment and inflation in Turkey for the monthly data from 2006 to 2011. The Autoregressive Distributed Lag (ARDL) Bounds test was conducted and the findings showed that unemployment negatively affects inflation in the short run but there is no causal connection in the long run. Ismael and Sadeq et. al [7] explored the connection between unemployment and inflation in Palestine for the quarterly data from 1996:2 to $2015: 3$. The study conducted the co-integration and Granger-causality tests and the findings revealed that inflation can affect unemployment negatively in the long run but positively in the short run. Haug and King (2011) [6] also investigated the long-run connection between inflation and unemployment in the United States for the period 1952 to 2010. The band-pass filter approach was used and the findings however showed a positive connection between inflation and unemployment. Therefore, a rise in inflation rate can result in higher unemployment rate.

Several studies examined the connection between inflation and unemployment in numerous countries and the existence of the Phillips curve can be confirmed. Katria et al. [9] selected 8 SAARC countries including Afghanistan, Bangladesh, Bhutan, India, Maldives, Nepal, Pakistan and Sri Lanka, and 6 expected countries of SAARC, namely, Republic of China, Russia, Indonesia, Iran, Myanmar and South Africa to analyze the connection between inflation and unemployment for the same period of 1980-2010. The analysis was based on the multiple regression and the results indicated that there is a negative connection between inflation and unemployment rate in the SAARC Countries. Therefore, this finding is similar to the Phillips curve. 
Bhattarai et. al [10] chose 28 OECD countries to examine the connection between inflation and unemployment for the period 1990:1-2014:4. The panel co-integration and panel granger causality tests were performed and the study showed varied findings whereby a significance of a negative connection between inflation and unemployment in some countries including Australia, Denmark, France, Italy, Netherlands, Spain, New Zealand, the UK and the US. However, different results of no connection were found in Austria, Germany, Israel and Norway. Surprisingly, a positive connection was ascertained in Korea, Russian and Slovak Republic.

\section{Research Methodology}

This study used data on unemployment rate and inflation rate from 10 high-income countries. The data from 1990 to 2014 were analyzed to see the existence of trade-off relationship between inflation rate and unemployment rate. The panel data methods were employed in this study as these methods are more powerful than times series methods. The panel unit root tests were conducted to see the stationarity of the data. Then the panel cointegration tests were performed to see the co-integrating relationship. The panel Granger causality tests were carried out to explore the existence of the Phillips curve in the short run. The equation for the simple Phillips curve is as follows:

$$
\mathrm{IR}_{\mathrm{t}}=\beta_{1}+\beta_{2} \mathrm{UR}_{\mathrm{t}-1}+\varepsilon_{\mathrm{t}}
$$

Where

IR represents inflation ration rate

$\beta_{1}$ is constant

$\beta_{2}$ represents the unemployment rate

$\varepsilon$ is the error correction terms

There are various tests of unit root that can be conducted in the panel data analysis such as Levin, Lin and Chu (LLC), Im, Pesaran and Shin (IPS) and Breitung. However this study employed LLC and this test is enough to see the stationarity of the data. This study is easy in making estimation and widely used in empirical studies.

After the unit root tests were conducted, the panel co-integration tests were performed to see the existence of a co-integration between the two variables (inflation rate and unemployment rate). The panel co-integration proposed by Pedroni et. al [11] is employed to explore the existence of a long-run co-integration between inflation rate and unemployment rates. Predoni introduced three group mean panel statistics for panel co-integration. Two sets of statistics were proposed and the first set of three statistics based on pooling the residuals within the dimension of the panel. Therefore, the equations for the statistics as follows:

$$
\begin{aligned}
& \mathrm{Z}_{\hat{\mathrm{v}}, \mathrm{N}, \mathrm{T}}=\mathrm{T}^{2} \mathrm{~N}^{3 / 2} \sum_{\mathrm{i}=1}^{\mathrm{N}} \sum_{\mathrm{t}=1}^{\mathrm{T}} \hat{\mathrm{L}}_{1 \mathrm{i}}^{2} \hat{\mathrm{e}}_{\mathrm{i}, \mathrm{t}}^{2}
\end{aligned}
$$

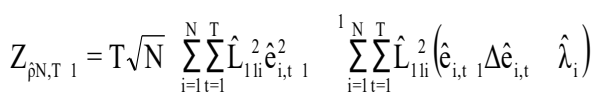

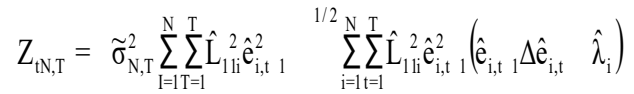

The second set of the statistics are based on pooling residuals between the dimension of the panel and it follows for a heterogeneous autocorrelation parameter across members and the equations are as follows:

$$
\begin{aligned}
& \widetilde{Z}_{\hat{\rho N}, \mathrm{~T} 1}=\sum_{\mathrm{i}=1}^{\mathrm{N}} \sum_{\mathrm{t}=1}^{\mathrm{T}} \hat{\mathrm{e}}_{\mathrm{i}, \mathrm{t}}^{2} 1 \sum_{\mathrm{t}=1}^{1}\left(\hat{\mathrm{e}}_{\mathrm{i}, \mathrm{t} 1} \Delta \hat{\mathrm{e}}_{\mathrm{i}, \mathrm{t}} \quad \hat{\lambda}_{\mathrm{i}}\right) \\
& \widetilde{\mathrm{Z}}_{\mathrm{tN}, \mathrm{T}} 1=\sum_{\mathrm{i}=1}^{\mathrm{N}} \sum_{\mathrm{t}=1}^{\mathrm{T}} \hat{\mathrm{e}}_{\mathrm{i}, \mathrm{t} 1}^{2} \sum_{\mathrm{t}=1}^{1 / 2}\left(\hat{\mathrm{e}}_{\mathrm{i}, \mathrm{t} 1} \Delta \hat{\mathrm{e}}_{\mathrm{i}, \mathrm{t}} \quad \hat{\lambda}_{\mathrm{i}}\right)
\end{aligned}
$$

This study also conducted the VECM test with a dynamic error correction term based on the analysis in Holtz-Eakin et al. (1989). The empirical models are as follows:

$$
\begin{aligned}
& \Delta I R_{i t}=\alpha_{1 t}+\sum_{p=1}^{m} \alpha_{11 i p} \Delta I R_{i t-p}+\sum_{p=1}^{m} \alpha_{12 i p} \Delta U R_{i t-p}+\alpha_{1 i} E C T_{i t-1}+\mu_{1 i t} \\
& \Delta U R_{i t}=\alpha_{2 t}+\sum_{p=1}^{m} \alpha_{21 i p} \Delta U R_{i t-p}+\sum_{p=1}^{m} \alpha_{22 i p} \Delta U R_{i t-p}+\alpha_{2 i} E C T_{i t-1}+\mu_{2 i t}
\end{aligned}
$$

Where $\Delta$ is the lag operator, $\mathrm{p}$ represents the lag length. The equations show the directional relationship between inflation rate and unemployment rate. In the short run if $\mathrm{H}_{0}: \alpha_{12 \mathrm{ip}}=0$ for all $\mathrm{i}$ and $\mathrm{p}$, it indicates that unemployment rate does not Granger cause inflation rate and if $\mathrm{H}_{0}$ : $\alpha_{22 \mathrm{p}}=0$ for all $i$ and $p$, it suggests that inflation rate does not Granger cause unemployment rate.

\section{Finding}

Results of the panel unit root tests based on the LLC, IPS, ADF and PP are presented in Table 1. The results show that at first difference, the null hypothesis is rejected. Therefore the two variables (inflation rate and unemployment rate) are stationary at first difference. 
Table 1: Unit Root Results

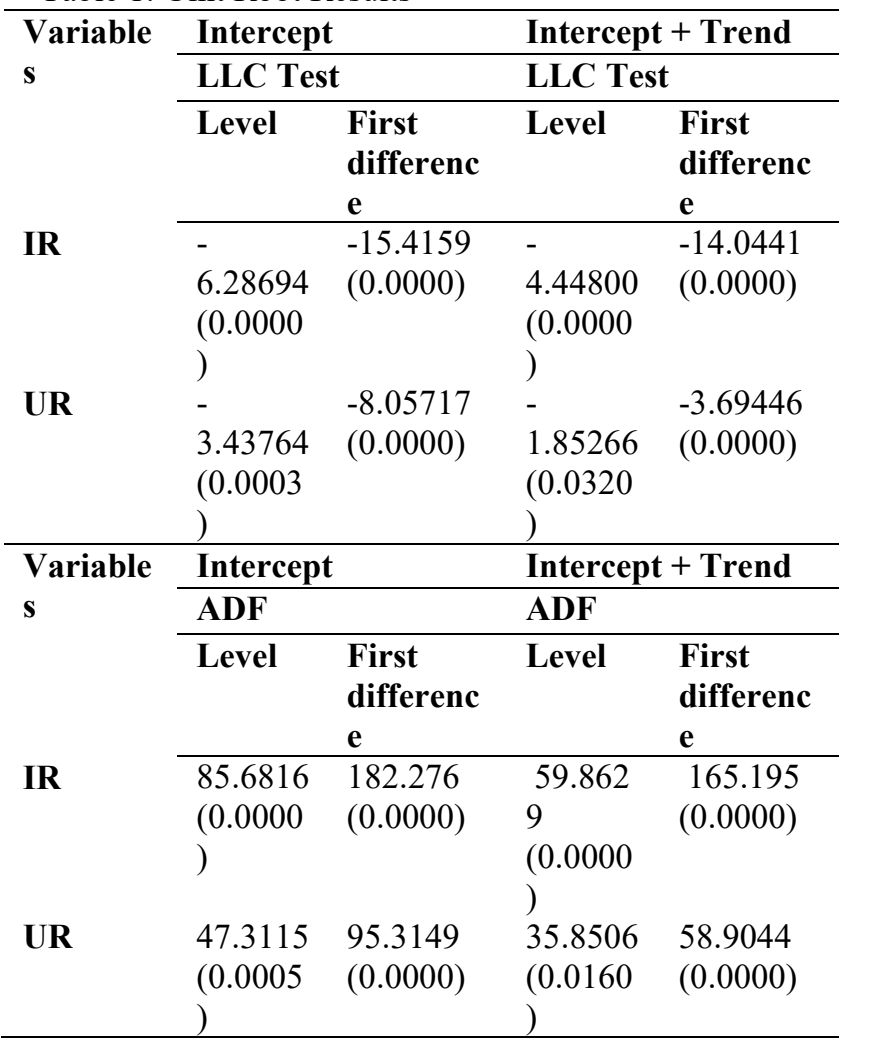

Note: $*$ and $* *$ indicate the rejection of the null hypothesis of non-stationary at $1 \%$ and $5 \%$ significance level, respectively. In addition, $\mathrm{P}$-values are in brackets.

Results of the panel Co-integration test are recorded in Table 2. For all the statistics, the null hypothesis of no co-integration can be rejected and thus suggesting inflation rate and unemployment rate are co-integrated in 10 selected high-income countries.

Table 2: Panel Co-integration Results

\begin{tabular}{lcccc}
\hline & \multicolumn{2}{c}{ Intercept } & \multicolumn{2}{c}{ Intercept + Trend } \\
\hline $\begin{array}{l}\text { Within } \\
\text { Dimensio }\end{array}$ & $\begin{array}{c}\text { Statistic } \\
\text { / Prob. }\end{array}$ & $\begin{array}{c}\text { Statistic } \\
\text { / Prob. }\end{array}$ & $\begin{array}{c}\text { Statistic } \\
\text { / Prob. }\end{array}$ & $\begin{array}{c}\text { Statistic } \\
\text { / Prob. }\end{array}$ \\
\hline Panel v- & 2.25632 & 2.11018 & - & - \\
Statistics & 9 & 1 & 0.15829 & 0.45431 \\
& $(0.0120)$ & $(0.0174)$ & 1 & 4 \\
& & & $(0.5629$ & $(0.6752)$ \\
Panel & - & & ) & \\
rho- & 3.85883 & 4.54404 & 2.28268 & 2.89778 \\
Statistics & 9 & 2 & 4 & 4 \\
& $(0.0001)$ & $(0.0000)$ & $(0.0112)$ & $(0.0019)$ \\
Panel PP- & - & - & - & - \\
Statistics & 4.39703 & 4.98647 & 4.20664 & 5.04218 \\
& 7 & 4 & 0 & 6 \\
& $(0.0000$ & $(0.0000)$ & $(0.0000)$ & $(0.0000)$ \\
& ) & & & \\
Panel & - & - & - & - \\
ADF- & 4.04247 & 4.85392 & 4.04516 & 5.01844 \\
Statistics & 4 & 6 & 4 & 2 \\
& $(0.0000)$ & $(0.0000)$ & $(0.0000)$ & $(0.0000)$
\end{tabular}

Between

Dimensio

$\begin{array}{lcc}\text { noup } & - & - \\ \text { rho- } & 3.01140 & 1.63783 \\ \text { Statistics } & 2 & 5 \\ & (0.0013 & (0.0507) \\ & ) & - \\ \text { Group } & - & 5.63186 \\ \text { PP- } & 5.74056 & 5 \\ \text { Statistics } & 2 & (0.0000) \\ & (0.00000 & \\ & - & - \\ \text { Group } & - & 5.03243 \\ \text { ADF- } & 5.44284 & 6 \\ \text { Statistics } & 7 & (0.0000) \\ & (0.0000) & \end{array}$

Results of the FMOLS tests are presented in Table 3. The results show that there is a significant effect of unemployment rate on inflation rate with feedback in the long run. The negative values of the coefficients suggest that there are negative relationships. Therefore an increase in unemployment rate can cause inflation rate to increase simultaneously and vice versa.

Table 3: FMOLS Results

\begin{tabular}{lll}
\hline \multicolumn{2}{l}{ Dependent Variable $=$ UR } \\
\hline & \multicolumn{1}{l}{ Coefficient } & Prob. \\
\cline { 2 - 3 } IR & $-0.200295^{* *}$ & 0.0325 \\
\hline \multicolumn{2}{l}{ Dependent Variable $=$ IR } \\
\hline \multirow{3}{*}{ UR } & Coefficient & Prob. \\
\cline { 2 - 3 } & $-0.178032^{* *}$ & 0.0275 \\
\hline
\end{tabular}

Note: $* *$ indicates the rejection of the null hypothesis of non-stationary and 5\% significance level.

Results of the panel VECM are recorded in Table 4. The results show that the coefficient of the error correction term (ECT) is negative and significant, thus supporting the long-run relationship between inflation rate and unemployment rate in 10 selected high-income countries. Apart from that the results also indicate that unemployment rate can influence inflation rate negatively in the short run. Therefore, a rise in unemployment rate can reduce inflation rate in the short run.

Table 4: Panel Granger Causality based on VECM

\begin{tabular}{cccc}
\hline $\begin{array}{c}\text { Dependent } \\
\text { variable: } \\
\Delta \mathbf{U R}\end{array}$ & & & \\
\hline Variables & $\Delta \mathbf{I R}$ & Constant & ECT $_{\mathbf{i}-1}$ \\
Coefficients & $0.008233^{*}$ & -0.010768 & $-0.100754^{*}$ \\
& $(0.8520)$ & $(0.8410)$ & $(0.0000)$ \\
\hline $\begin{array}{c}\text { Dependent } \\
\text { variable: }\end{array}$ & & & \\
$\Delta$ IR & & & \\
\hline Variables & $\Delta \mathbf{U R}$ & $\mathbf{C o n s t a n t}$ & ECT $_{\mathbf{i}-1}$ \\
Coefficients & $-0.440630^{*}$ & -0.137570 & -0.082795 \\
& $(0.0001)$ & $(0.1289)$ & $(0.0914)$ \\
\hline
\end{tabular}

Note: * indicates the rejection of the null hypothesis of non-stationary and $5 \%$ significance level. 


\section{Conclusion}

This study aims to investigate the existence of the Phillips curve in high-income countries for the period 1990-2014, using the panel data analysis. The panel unit root test was conducted and the results show that all the data becomes stationary at first difference. Then, the panel co-integration test was performed and the results show that there is a co-integrating relationship between inflation rate and unemployment rate. The FMOLS method was employed and the results show that there is a negative relationship between inflation rate and unemployment rate in the long run. Results of the VECM test reveal that the value of ECT is negative and significant; therefore, it can confirm that there is a long run relationship between inflation rate and unemployment rate. Apart from that the VECM test can show the relationship in the short run. Based on the results, it shows that there is a negative relationship between inflation rate and unemployment rate.

Therefore, all the results confirm the existence of the Phillips curve in the both short and long run. These findings are important for policy implications. If policy makers formulate policies to stabilize inflation, the country has to accept high unemployment rate and vice versa. This is because there is a trade-off relationship between inflation rate and unemployment rate.

\section{References}

1. Che Mansor bin Che Tom, Al-zeaud, H., \& Alhosban, S. Does Phillips curve really exist? An empirical evidence from Jordan. European Scientific Journal, 11(10), (2015)

2. Dritsaki, C. \& Dritsaki, M., Inflation, unemployment and the NAIRU in Greece', Procedia Economics and Finance, 1, 118-127, (2012)

3. Friedman, M. The Role of Monetary Policy, The American Economic Review, 58(1), 1-17, (1968)

4. Furuoka, F, Does the Phillips curve really exist? New empirical evidence from Malaysia,

Economics Bulletin, 5 (16), 1-14, (2007)

5. Furuoka, F. \& Munir, Q., "Unemployment and Inflation in Malaysia: Evidence from Error Correction Model", Malaysian Journal of Business and Economics, 1 (1),35-45, (2014)

6. Ifred A. Haug \& Ian P. King., "Empirical Evidence on Inflation and Unemployment in the Long Run". Research Paper, 1128, (2011).

7. Ismael, M. \& Sadeq, T. , Does Phillips Exist in Palestine? An Empirical Evidence. MPRA Paper No. 70245, (2016)

8. Karahan, O., O. Colak and O.F. Bolukbaşı, Tradeoff between Inflation and Unemployment in Turkey, The Empirical Economics Letters, 11(9): 973-980, 2012

9. Katria, S., N.A. Bhutto, F. Butt, A.A. Domki, H.A. Khawaja \& J. Khalid, Trade off between inflation and unemployment. International
Conference on Business Management. 1-18, 2011

10. Bhattarai, K. Unemployment-inflation tradeoffs in OECD countries. Economic Modelling, 58, 93-103, (2016)

11. Pedroni, P., Panel Cointegration: Asymptotic and Finite Sample Properties of Pooled Time Series Tests with an Application to the PPP Hypothesis, Working Papers in Economics,no. 95 - 013, Indiana University, Bloomington, IN, (1995)

12. Phillips, A.W. The Relationship between unemployment and the rate of change of money wage rates in the United Kingdom, Economica, 25, 258-299, (1958)

13. Resurreccion, P. F. , Linking unemployment to inflation and economic growth: Toward a better understanding of unemployment in the Phillipines, Asian Journal of Economic Modelling, 2(4), 156-168, (2014)

14. Schreiber, S., and Wolters, J. The Long-Run Phillips Curve Revisited: Is the NAIRU Framework Data-Consistent? Journal of Macroeconomics, 29 (2), 355-367, (2007)

15. Shaari, M.S., Rani, M.J.A., Ismail, M.S., \& Hussain, N.E. Inflation and unemployment in Malaysia. Malaysian Technical Universities Conference on Engineering and Technology (MUCET) 2012, (2012) 